\title{
STRESS INOCULATION TRAINING: A CASE STUDY IN GYMNASTICS
}

\author{
R. MACE, DipPE, MA*, C. EASTMAN, BSc, MSc, PhD** and D. CARROLL, BSc, PhD** \\ *Newman College of Education, Birmingham \\ **Psychology Department, University of Birmingham
}

\begin{abstract}
A young female gymnast of regional squad potential had ceased to make progress when she resumed training after a series of injuries and was given stress inoculation training to help her to regain her form. Preliminary interviews revealed that she had developed a number of negative self-statements and images which, it was hypothesised, may have been contributing towards her lack of progress. In order to replace these with positive self-statements and images a treatment programme of eight training sessions was implemented. Recorded interviews and subsequent comparison of comments made by the subject before and after the intervention programme, indicated that the training had been successful. This was endorsed by the coaches who reported an improved attitude to training and rapid progress in skill learning.
\end{abstract}

\section{INTRODUCTION}

In recent years techniques developed in clinical psychology, have been increasingly used in sport psychology and a closer relationship has been developed between these two fields of study (Yaffe, 1981; Kincey, 1981). The constant search for improved athletic performance has caused many athletes to train and compete under conditions of extreme psychological stress. Accordingly, stress management techniques, originally devised for phobic patients have been adapted and used to help athletes cope with stress and enhance their performance (Feltz and Landers, 1980; De Witt, 1980; Borkovec, 1981). One technique which has received increasing interest because of its flexibility is stress inoculation training (Meichenbaum, 1977). This has been used successfully in basketball (Harrison and Feltz, 1981), running (Ziegler et al, 1982) and abseiling (Mace and Carroll, 1985).

Stress inoculation training emphasises the role of selfstatements in developing coping skills to combat stress which may arise in sport from fear of injury, pain or failure. The important influence of fear on performance has been widely acknowledged by sports performers (Newman, 1981). Fear can cause a loss of form in many sports and is often associated with 'mental blocks' and 'freezing'. These are frequently accompanied by the experience of inappropriate mental images, such as seeing onself being injured, and the development of a set of negative selfstatements. In such cases, stress inoculation training is potentially very valuable in helping a performer to overcome these problems.

\section{CASE HISTORY AND BEHAVIOURAL ASSESSMENT}

The subject was a twelve year old girl who had shown outstanding ability at gymnastics when she was nine years old. She was club champion two years in succession, when she was nine and ten. If she had progressed as expected, she would have made the regional squad at the age of twelve. Unfortunately, she suffered a series of injuries which prevented her from training for some months and appeared to affect her attitude when she started again. She

Address for correspondence:

R. D. Mace

Newman College of Education

Genners Lane

Bartley Green

BIRMINGHAM B32 3NT entered the club championship when she was eleven but came last. A few months later she was eliminated from the National Squad. She continued to train but although she still had a lot of ability and appeared to have the right mental approach she developed a number of 'mental blocks' which her coach described as the 'chicken syndrome'. The problem became worse, she began to fail to perform moves which she had done before and it became increasingly difficult to teach her new moves. It was suggested by the coach that she should receive some specialist help in overcoming her mental blocks and she readily agreed to this.

Many athletes are well aware of the value of 'psyching themselves "up"' as opposed to the dentrimental effect on performance of "psyching themselves "down" or "out"'. This was the case with a number of other gymnasts in the same club. Earlier investigations had revealed that most of them had developed a very good mental approach. Immediately prior to performing they visualised themselves performing well and made positive self-statements, for example; "I won't fall off the bars today". It appeared that they had developed spontaneously these techniques in order to 'psych' themselves into the optimum mental state.

This was not the case with the subject in the study. During the preliminary interviews, which were audiotaped, the subject was asked at some length about her thoughts and feelings during training and competition. It became clear that when she was about to attempt difficult moves she generated a set of negative self-statements, examples of which included;

"What if I miss the Bar!" "What if I over-rotate ... it's OK in the foam pit but I could kill myself if I landed on the floor". She also frequently experienced a voice from inside her saying "I can't". She tried hard to eliminate these selfstatements and to develop a positive attitude but reported that when she told herself not to think like that she immediately began to have bad thoughts.

The girl also experienced images which were not conducive to developing a good mental approach. She had a recurring mental image of a person over-rotating and landing on her head and although she tried hard to visualise this person performing the move skilfully the person in her mind kept over-rotating. She freely discussed her series of injuries and did not appear to have developed a psychological problem as a result of one specific accident. However, she had experienced some considerable fear on 
one occasion when she had fallen from the asymmetrical bars. Although not injured she reported that she was frightened of experiencing such intense fear again.

\section{TREATMENT}

In order to replace the negative self-statements and images with positive ones, a programme of stress inoculation training (Meichenbaum, 1977) was devised. This comprised eight treatment sessions which covered the education, rehearsal and application phases. The education phase comprised a discussion of the arousal-performance relationship with reference to performing gymnastic skills. In the rehearsal stage the subject was taught initially a simple relaxation technique. While in a relaxed state, she visualised gymnastic moves that she could perform to a high standard and rehearsed positive self-statements immediately prior to seeing herself do the moves perfectly. In subsequent sessions she was asked to visualise moves which she found difficult and were causing her some problems. Training was again given in making positive selfstatements immediately prior to visualising the move, for example;

...tell yourself that you can cope with any distractions . . . if a voice says "I can't" imagine that it is coming from a record ... feel yourself reach out and move the needle over and hear the voice say "yes I can, I've learnt to concentrate better now" ... tell yourself if you have any bad images to just let them fade away as you concentrate on what you have to do.'

In the application phase the counsellor worked with the subject in the gymnasium initially on moves which she could perform easily. In subsequent sessions she attempted increasingly difficult gymnastic moves using her new coping skills.

At the later stages her coaches were involved giving physical support, guidance and feedback. The sessions generally progressed well but during one session she 'froze' when attempting a move without support on the asymmetrical bars. However, she was able to perform it at a lower height with support.

Following the intervention programme the counsellor attended a two hour training session during which the subject attempted many difficult gymnastic skills. At various times she was asked to describe the thoughts and feelings she experienced immediately prior to performing those feats of gymnastic skill.

\section{RESULTS}

After the intervention programme, the subject's comments during the training session indicated that stress inoculation training had been successful in developing a set of positive self-statements and images. She reported that she was able to concentrate much better and was able to visualise a skill immediately before performing it. Following her performance she was able to concentrate on the parts that had been executed skilfully and could think positively about the aspects that needed improving. She reported that she no longer had "bad images" or heard a voice inside saying "I can' $t$ ". It was interesting to note from her comments that she was able to adapt the cognitive techniques that she had been taught to suit different situations. For example, before performing a skill on the tumbling mats she felt that it was best to visualise the move during, rather than prior to, her run up.

During the two hour assessment the subject enjoyed a very good training session. She performed successfully a vault which had been causing her some problems and for the first time in twelve months successfully completed a routine on the asymmetrical bars. Her coaches reported that she was training with more determination and that they were pleased with her progress.

At the time of writing, subsequent training sessions have been successful with the subject making good progress. On occasions she experienced some difficulty with the move on the asymmetrical bars but eventually regained this skill. A few weeks after the intervention programme she performed very well in a competition to gain a silver medal and a month later she won the club championships to become senior ladies champion.

\section{DISCUSSION}

A comparison of recorded comments made by the subject prior to and after intervention show that her mental approach had become more positive. She appeared to be using visualisation and self-statements successfully and was very happy to be making good progress. She responded very well during the treatment sessions and thought that the 'mental tricks' were very helpful. However, despite the apparent success of the intervention programme it cannot be concluded that the stress inoculation training programme was responsible for the change in attitude and improvement in performance. The fact that she had received extra attention from her coach and a counsellor may have had a significant influence. Also, the graduated return to training may have been an influential factor. However, the subject had not received training for any other mental preparation strategy and this supports the view, that stress inoculation training established or re-established positive self-statements and mental images.

Prior to the intervention the girl had a particular problem with a comparatively easy skill on the asymmetrical bars and during the application phase this move again caused some difficulty. It is possible that she tried to make progress too quickly but this does indicate that counsellors must be particularly sensitive to subjects' emotions during the application phase, and now she is making very good progress. She has regained this particular skill and winning club championships has given her considerable pleasure.

In order to confirm the potential value of stress inoculation training for sport, further research is necessary. In therapeutic work such as this, follow-up studies should be carried out in order to examine for the continuing use of stress inoculation coping skills, the ideosyncratic adaptation of these procedures, and any possible generalisations. Further studies should also examine performance changes since the reason for developing a positive mental approach is to enhance skilled performance. It would also be particularly interesting to monitor psychophysiological measures in addition to collecting self report data. Research carried out with sport parachutists by Fenz and Jones (1974) showed considerable differences in heart rate measures between experienced performers and novices. This suggested some form of 
emotional control. An examination of psychophysiological measures before and after stress inoculation training, together with well designed group experiments, would provide valuable information on the effect of the intervention and on the relationship between self-report and psychophysiological changes.

It can be concluded, therefore, that while the present observations do not unequivocally establish stress inoculation as the instrument of change in this context, they give support to the view that it is a very useful technique for stress management in sport.

\section{References}

Borkovec, T. D., 1981 "Stress management in athletics: An overview of cognitive and physiological techniques". Motor Skills: Theory into Practice 5 (1): 45-52.

De Witt, D. J., 1980 "Cognitive and biofeedback training for stress reduction with university athletes". Journal of Sport Psychology 2: 288-294.
Feltz, D. L. and Landers, D. M., 1980 "Stress management techniques for sport and physical education". Journal of Physical Education and Recreation 5 (2): $41-43$.

Fenz, W. D. and Jones, G. B., 1974 "Cardiac conditioning in a reaction time task and heart rate control during real life stress". Journal of Psychosomatic Research 18: 199-203.

Harrison, R. P. and Feltz, D. L., 1981 "Stress inoculation for athletes: Description and case example". Motor Skills: Theory into Practice 5 (1): 53-61.

Kincey, J., 1980 "Sport psychology and clinical psychology: What value in a closer relationship". International Journal of Sport Psychology 2: 288-294.

Mace, R. and Carroll, D., 1985 "The control of anxiety in sport: stress inoculation training prior to abseiling". International Journal of Sport Psychology 16: 165-175.

Meichenbaum, D., 1977. Cognitive Behaviour Modification. New York, Plenum Press.

Newman, S., 1981 "Fear, the apprehensive athlete". Coaching Review 4 18-23.

Yaffe, M., 1981 "The contribution of clinical psychology to sports medicine". British Journal of Sports Medicine 15 (1) 60-63.

Ziegler, S. G., Klinzing, J. and Williamson, K., 1982 "The effects of two stress management training programmes on cardiovascular efficiency". Journal of Sport Psychology 4: 280-289.

\section{BOOK REVIEW}

Title:

\section{HOW TO WRITE AND PUBLISH A SCIENTIFIC PAPER}

Author:

Robert A. Day

Publisher:

ISI Press, Philadelphia, USA

Price: $\$ 14.95$ soft cover $\$ 20.95$ hard cover 181 pages. Second Edition

ISBN 0-89495*021-5

This volume is one of a series published by ISI Press. The series is designed to improve the communication skills of professional men and women as well as students embarking upon professional careers. It is certainly a must for all those whose work involves preparing manuscripts for publication in scientific journals. Many of the currently available books on scientific writing and publishing attempt to cover this broad area of enforced creativity in a single volume while Robert Day confines his book to the essential requirements for publishing a paper. I have often considered the many books on this topic to be part of a covert plot to intimidate the reader into not writing and so leave the field clear for the authors of these so-called 'self-help' texts. This is not the case with Robert Day's book which throws a lifeline to all of us swamped by demands to publish scientific papers.

In this book he takes his readers step by step through the whole process of preparing and presenting a manuscript for publication in what I can only describe as a kindly and amusing way. Each chapter has a title and an accompanying quotation which is so apt and thought-provoking that the reader finds it easy to linger and ponder before delving into the contents of the chapter. The chapters follow the format of a scientific paper devoting a chapter on How to Prepare a Title, List Authors, Prepare the Abstract, Write the Introduction, Write the Methods and Materials Section, Write the Results Section and design tables and illustrations and Write the Discussion and Reference list. In each of these chapters there is not only sound advice which represents distilled wisdom of an experienced editor but also so many amusing anecdotes that it is almost worth reading for these alone. For example on the problem of lengthy titles he describes and cites papers whose titles almost take longer to read than the paper itself! Or on the problem of authorship and whose name should be on the paper he cites a paper on which there were twenty-seven authors and the paper only contained twelve paragraphs!

In the latter half of the book he extends his welcomed and easy to read advice to writing conference reports, book reviews, theses and even offers some tips on how to prepare a paper for oral presentations. On the nuts and bolts side of preparing a manuscript he covers the issues of Ethics, Rights and Publishing Permission as well as the Use and Misuse of English and of course how to avoid the "jargon trap" into which we are all too often seduced in our hurry to meet deadlines.

The Appendices are full of useful information which will inevitably result in them becoming one of the much thumbed sections of this book and not sadly neglected as in many other texts in which they appear to be an after-thought of a publisher with an eye for size rather than content. For example there is an appendix which deals with "Abbreviations That May Be Used Without Definition In Table Headings" as well as one on "Words And Expressions To Avoid". In addition the appendix on "Prefixes and Abbreviations for SI Units" is mot useful and will help the would-be author avoid annoying the Editors to whom he sends his manuscripts by not using the wrong or inappropriate abbreviations.

In conclusion this is a "user-friendly" text in which the author shares his experience with the reader in such a way that it encourages one to put pen to paper or finger(s) to keyboard. I strongly recommend this book to all would-be authors and hope that not only will they obtain great practical benefit from it but that they will enjoy the book for its humour and style. 